CSDM Views 1

\title{
Current issues in the acquisition of multirole fighters for the Bulgarian air force
}

\author{
Venelin Georgiev
}


Associate Professor Dr Venelin Georgiev works at the Centre for security and defense management, in Institute on Communication and Information Technologies - Bulgarian Academy of Sciences. His professional experience and interests are related to the systems of aircrafts maintenance, program defense resource management, defense acquisition and risk management. Derivative 2.5 Bulgaria License

Editors: Todor Tagarev, Velizar Shalamanov, Venelin Georgiev, Valeri Ratchev 
In any way to be defined, national security remains a generally recognized value, a major priority and a significant interests, which needs to be guaranteed and defended. Guaranteeing national security among other things requires the maintenance and development of appropriate in quality and sufficient quantity set of defense capabilities that are relevant to the current existing threats and the vulnerability of our country to these threats. Defending national security is related to the implementation of active and effective internal and external common policy, particularly national security policy that gives our country a position and role as a neighbor and partner consuming, but also generating security on the national territory, in the region of European and EuroAtlantic community.

On this basis, a private, but significant issues related to building capacity to guarantee national security, in the context of union security, is the purchase of multirole aircraft for the needs of BGAF. The significance of this investment project, measured by the expected effects, the amount of necessary financial resources and the associated investment risk is among the reasons in the public sphere and the media to run various discussions, to ask different questions and to hear different views of politicians, professionals, experts and citizens ${ }^{1}$. Unfortunately much of these discussions have been narrow in scope and browsing individual nuances of a such complex issue, that is the question of the meaning, content, technology and cost and use of multirole aircraft for BGAF. As examples of questions on the content of such discussions may be indicated: whether multirole aircraft to be new or "second hand", whether to purchase 12 or 18 pieces, if preferred manufacturer to be Company $\mathrm{X}$ or Company $\mathrm{Y}$, etc.

Finding a rational, analytical justified, resource support and effective solution for such a big and complex issue requires entry system built and structured basis, but also attract a wide range of proven experts and specialists from various institutions to carry out necessary tests, evaluations, analysis and forecasting in the interest of the final management decision. Attempts to create such a structured basis for discussion on the issue of multirole aircraft to the BGAF should take into account the existence of different thematic areas, different hierarchical levels and different perspectives that need to be simultaneously considered and balanced when formulating the investment decision. Examples of related subject areas may be referred to the political, professional, expert, legal, investment, innovation, social and other fields. Arguments in the definition of thematic areas and plug the questions (respectively answer) associated with the investment project for the purchase of multirole aircraft for the BGAF can be easily identified. Definitely should be noted that an investment project of this scale is an important tool not only for domestic but also for foreign policy. As such it should be used in the best possible way to reap the dividends related political, economic and social fields. The opinions of those who discussed in a policy are in different directions, but that does not mean that those comments and questions should not be analyzed in seeking possible balanced response ${ }^{2}$.

Among the community of professionals, ie people who will operate and maintain multirole aircraft, also run a discussion in the focus of which are the issues on the need to acquire multirole aircraft that will allow the Bulgarian pilots to continue their preparation and execution of missions and associated tasks (eg Air Policing). In this area, opinions are characterized by a higher degree of uniformity ${ }^{3}$.

\footnotetext{
1 Advanced Air and Air Defence Capabilities. Information \& Security: An International Journal, Vol 25, 2010. http://infosec.procon.bg/contents/vol_25.htm

2 Nikolov $\mathrm{S}$. There is no an alternative for the project of purchasing multirole fighters for BGAF. http://www.csr-bg.com/Istrebiteli.htm

3 MG Constantine Popov. Contribution of the New Main Combat Aircraft to Bulgaria's Defence Capabilities. Information \& Security: An International Journal, Vol 25, 2010.

http://infosec.procon.bg/contents/vol_25.htm
} 
Discussion on the expert level, ie between experts from different fields is the most pragmatic and devoid of emotions and perhaps precisely because of these reasons remain in the background. However, all should be clear that the expert position is based on the use of science and analytical models and methods, making it highly independent and uunaffected by emotions and personal preferences. This is particularly true for expert assessment and analysis of the economic rationality of various alternatives for multirole aircraft taking into account the financial constraints arising from the limited defense budget ${ }^{4}$.

The legal discussion on the acquisition of multirole aircraft for the BGAF is related to the adopted amendments to the Law on Bulgarian Defense and Armed Forces, under which the decision to launch the investment project in defense of this scale is in powers of the National Assembly. And the question here is if a parliamentary institution has sufficient capacity to carry out qualitative and scientifically based assessments and analysis of alternatives for investments in defense, on which to decide receiving approval from all classes who take the treatment and are associated with the outcome of investment project. In the absence of sufficient analytical potential, as quality and quantity, the question becomes what are the opportunities to parliament to deal with its new major responsibilities. One possible approach in these circumstances is to be awarded a project by independent organizations (eg research institutes with a capacity for strategic management of Defence) to develop appropriate procedures for assessment and analysis of investment projects and the other approach is outsourcing the analytical work of external independent organization (outside of institutions in defense) and use the results when making the final investment decision. Any of the two to be elected, the election must be timely so as not to reach a familiar condition in which the last moment should make responsible decisions without analytical, scientific justification that would always raises doubts about the lack of transparency and corruption risk.

Implemented appropriately an investment project, as proposed acquisition of multirole aircraft for the BGAF, would be a noticeable measure of innovative features both as a product, process and organizational innovation. Product, because there will be a new type of aircraft with options for solving a wide range of tasks related to national security. Process, because the processes to operate and maintain the new type of multirole aircraft, based on technical condition will be new to the same processes applied to the currently used aircraft in which a guiding principle (and problem) is in operation, based on the resource. Organizational, because with the introducing of the new type of multirole aircraft would probably require a change in the organizational structure of units (squadrons) involved in its operation, maintenance and repair. Depending on the chosen solution, the project of purchasing multirole aircraft for the BGAF may have characteristics of marketing innovation, as if it comes to understanding the usefulness of the joint (as an example: with Romania) acquisition and exploitation of the appropriate type multirole aircraft ${ }^{5}$. The advantages of such a decision are varied: from sharing the financing and risk to the use of economies of scale that would give advantages to buyers in negotiating the terms of the transaction.

Do not underestimate the social aspect of buying a multirole aircraft for the simple reason that the creditors of the investment project will be citizens through their taxes. This at least requires the investment decision to ensure an adequate return in the form of effects related to national se-

4

Venelin Georgiev. Embedding Affordability Assessment in the Analysis of Alternatives in Defense Modernization Projects. Information \& Security: An International Journal, Vol 25, 2010.

http://infosec.procon.bg/contents/vol_25.htm

$5 \quad$ Sabi Sabev. Developing and Employing Expeditionary Capabilities: Key to Transforming Air Forces of Small NATO Nations. Information \& Security: An International Journal, Vol 25, 2010.

http://infosec.procon.bg/contents/vol_25.htm 
curity to justify and convince taxpayers to accept such an alternative to spending their financial resources.

The listed areas and issues, related to the decision of the project for acquisition of multirole aircraft for the BGAF are not pretentious nor aimed to be exhaustive. They come to the aid of one hand to demonstrate how difficult and complex is that issue and secondly to confirm the need to take account of the diverse and often conflicting views and recommendations when choosing a rational and effective management decision. No argument that a decision can be taken in another way, but such a decision is unlikely to get the support of society and will hardly bring the desired results and success measured by ensuring national security and contribution to EU and NATO security. 